\title{
Structural similarities and functional differences clarify evolutionary relationships between tRNA healing enzymes and the myelin enzyme CNPase
}

\author{
Gopinath Muruganandam ${ }^{1}$, Arne Raasakka ${ }^{2,3}$, Matti Myllykoski ${ }^{2}$, Inari Kursula, ${ }^{1,2,3}$ and Petri Kursula $a^{1,2,3^{*}}$ (D)
}

\begin{abstract}
Background: Eukaryotic tRNA splicing is an essential process in the transformation of a primary tRNA transcript into a mature functional tRNA molecule. 5'-phosphate ligation involves two steps: a healing reaction catalyzed by polynucleotide kinase (PNK) in association with cyclic phosphodiesterase (CPDase), and a sealing reaction catalyzed by an RNA ligase. The enzymes that catalyze tRNA healing in yeast and higher eukaryotes are homologous to the members of the $2 \mathrm{H}$ phosphoesterase superfamily, in particular to the vertebrate myelin enzyme $2^{\prime}, 3^{\prime}$-cyclic nucleotide 3'-phosphodiesterase (CNPase).
\end{abstract}

Results: We employed different biophysical and biochemical methods to elucidate the overall structural and functional features of the tRNA healing enzymes yeast Trl1 PNK/CPDase and lancelet PNK/CPDase and compared them with vertebrate CNPase. The yeast and the lancelet enzymes have cyclic phosphodiesterase and polynucleotide kinase activity, while vertebrate CNPase lacks PNK activity. In addition, we also show that the healing enzymes are structurally similar to the vertebrate CNPase by applying synchrotron radiation circular dichroism spectroscopy and small-angle X-ray scattering.

Conclusions: We provide a structural analysis of the tRNA healing enzyme PNK and CPDase domains together. Our results support evolution of vertebrate CNPase from tRNA healing enzymes with a loss of function at its N-terminal PNK-like domain.

Keywords: Cyclic phosphodiesterase, Polynucleotide kinase, Substrate specificity, Protein structure, 2H family, Evolution, tRNA splicing

\section{Background}

Eukaryotic tRNA processing is an essential process, by which newly synthesized immature pre-tRNA matures into functional tRNA. The processing of tRNA begins with endonucleolytic cleavage of the pre-tRNA into an intron and two tRNA halves that are healed and sealed by tRNA splicing. The $5^{\prime}$-phosphate ligation pathway, used by yeast and plants, involves the $5^{\prime}$-phosphate of the $3^{\prime}$-tRNA half as the junction phosphate of the new

\footnotetext{
* Correspondence: petri.kursula@uib.no

${ }^{1}$ Centre for Structural Systems Biology - Helmholtz Centre for Infection Research, German Electron Synchrotron (DESY), Hamburg, Germany

${ }^{2}$ Faculty of Biochemistry and Molecular Medicine \& Biocenter Oulu, University of Oulu, Oulu, Finland

Full list of author information is available at the end of the article
}

phosphodiester linkage $[1,2] .5^{\prime}$-phosphate ligation requires three enzymatic activities: a cyclic phosphodiesterase (CPDase), a polynucleotide kinase (PNK), and a ligase [1,3-5]. In contrast to yeast and plants, animal cells employ two different ligation pathways. The 3'-phosphate ligation pathway utilizes the 3 'phosphate of the $5^{\prime}$-tRNA half as the junction phosphate; this pathway was first detected in HeLa cell extracts [6]. The second pathway used by animal cells is a yeast-type $5^{\prime}$-phosphate ligation pathway, which has been detected in HeLa cell extracts and in the lancelet, Branchiostoma floridae [7, 8]. tRNA healing enzymes appear to be distant homologues of the $2 \mathrm{H}$ phosphoesterase superfamily, which is defined by the 
presence of two conserved $\mathrm{H}-\mathrm{x}-\mathrm{T} / \mathrm{S}-\mathrm{x}$ ( $\mathrm{x}$ is a hydrophobic residue) motifs [8-10].

The central kinase module of yeast (Saccharomyces cerevisiae) Trl1 and the N-terminal PNK domain of lancelet PNK/CPDase show resemblance to the bacteriophage T4 PNK and belong to the P-loop phosphotransferase superfamily. They contain the signature Walker A motif (P-loop), which is an NTP-binding site in most NTP-dependent phosphotransferases [8, 11-15]. Initial functional analysis of the kinase module of yeast Trl1, using single alanine mutations in the P-loop, revealed that the P-loop motif $\left({ }^{401} \mathrm{GCGKT}^{405}\right)$ is a determinant of NTP binding [16]. GTP is the preferred in vivo physiological substrate, and yeast Trl1 contains a single NTP binding site [16]. GTP dependence of the yeast Trl1 kinase domain has also been verified in vitro [17].

The CPDase domain of both yeast Trl1 and lancelet PNK/CPDase bears resemblance to phosphoesterases of the $2 H$ superfamily [8-10]. Although $5{ }^{\prime}$-P RNA ligases of fungi, plants, and animals share essential mechanistic features and key residues required for their PNK and CPDase activities, their overall sequence similarity is low. The presence of the P-loop or Walker A motif (G$\mathrm{x}-\mathrm{G}-\mathrm{K}-\mathrm{T} / \mathrm{S}, \mathrm{x}$ is any residue) in the $\mathrm{N}$-terminal domain and the two $\mathrm{H}-\mathrm{x}-\mathrm{T} / \mathrm{S}-\mathrm{x}$ motifs in the C-terminal domain of vertebrate $2^{\prime}, 3^{\prime}$-cyclic nucleotide $3^{\prime}$-phosphodiesterase (CNPase) indicates that the PNK/CPDase domains of yeast Trl1 (Sc PNK/CPDase) and the lancelet $(B f)$ PNK/CPDase are homologues of vertebrate CNPase $[8,18]$.

In most vertebrates, CNPase is abundantly expressed in the myelin sheath, a multilayered proteolipid membrane system. CNPase constitutes $4 \%$ of total myelin protein in the central nervous system (CNS) and $0.4 \%$ in the peripheral nervous system (PNS) [19]. CNPasedeficient mice develop progressive motor deficits and die prematurely due to diffuse brain axonal swelling and neurodegeneration [20]. However, it is not known whether the late onset of neurodegeneration is caused by the absence of the CNPase protein as a structural component of the myelin sheath or the absence of CNPase enzymatic activity. CNPase has been implicated in neurodegenerative disorders, such as multiple sclerosis and schizophrenia [21, 22]. A recent study showed that CNPase inhibits the assembly of infectious particles of several primate lentiviruses, including the human immunodeficiency viruses HIV-1 and HIV-2, by binding to the structural protein Gag [23].

The enzymatic activity of CNPase, the hydrolysis of 2 ',3'-cyclic nucleotides to 2 '-nucleotides, was detected in brain tissue in the 1960s [24]. Atomic structures of the C-terminal catalytic domain of human, rat, and mouse CNPase have illuminated the catalytic role of the $\mathrm{H}-\mathrm{x}-(\mathrm{T} / \mathrm{S})-\mathrm{x}$ motifs and other functionally important groups in the active site $[18,25-29]$. The structure and function of the $\mathrm{N}$-terminal domain of CNPase remain poorly characterized. The expression and purification of the $\mathrm{N}$-terminal domain is difficult compared to the C-terminal domain, limiting the availability and characterization of the molecule [30]. Although the Nterminal domain of CNPase contains the NTP-binding P-loop motif, and a study by Stingo et al. claims that nucleotide binding occurs in the N-terminal domain, it has not been experimentally proven, whether the interaction and hydrolysis take place exclusively in the $\mathrm{N}$ terminal domain, as only full-length CNPase was used in the experiments [31]. The $\mathrm{N}$-terminal domain of CNPase binds RNA, mediates dimerization, and interacts with calmodulin (CaM) in a calcium-dependent manner [27, 32]. CNPase has recently been found to bind microfilaments and act as an antagonist for myelin basic protein in myelin membrane compaction [33], suggesting a structural role - possibly independent of enzymatic CNPase activity.

Although the structure of the C-terminal phosphodiesterase domain of vertebrate CNPase has been determined, no high-resolution structures of either full-length CNPase or its N-terminal domain are available. The functional properties of vertebrate CNPase, such as interactions with membranes, cytoskeletal proteins, and RNA have been studied; however, the link between its function in the myelin sheath and its role in RNA binding is not clear. Hence, structural and functional characterization of PNK/CPDase would benefit, not only the field of tRNA splicing, but also studies on other members of the $2 H$ phosphoesterase family. Since $B f P N K / C P D a s e$ could be involved in a new class of $5^{\prime}$ $P$ RNA ligation, characterization of this enzyme might improve our understanding of the growing complexity of animal tRNA splicing. Despite genetic and biochemical analysis of PNK and CPDase domains of yeast Trl1, no structural information is available for any domain of the enzyme. Therefore, detailed biophysical and biochemical analysis of $S c$ Trl1 PNK/CPDase and BfPNK/ $\mathrm{CPDase}$ is warranted. We generated multiple expression constructs encoding different segments of the PNK/CPDase domains of yeast Trl1, as well as fulllength lancelet PNK/CPDase. An array of biophysical and biochemical methods was employed to characterize the proteins, including assays for activity, thermal stability, and folding of the PNK/CPDase domains.

\section{Methods}

Sequence and ligation independent cloning

The Protein Crystallographic Construct Design (ProteinCCD) metaserver was used to choose fragments from different domains of yeast and lancelet healing enzymes based on information acquired from various 
prediction servers for secondary structure, disorder, coiled coils, transmembrane segments, conserved domains, and domain linkers [34]. Multiple expression constructs encoding the PNK and CPDase domains of yeast tRNA ligase and full-length lancelet PNK/CPDase were assembled by sequence and ligation independent cloning (SLIC). The primers used are listed in (Additional file 1). Briefly, the DNA fragments of interest were amplified by polymerase chain reaction (PCR) from pET28a and pET20b plasmids harbouring ScTrl1 and BfPNK/CPDase, respectively [8]. The amplified products and linearized pET-his3C-LIC-amp vector (a kind gift from the Netherlands Cancer Institute) were separately treated with T4 DNA polymerase. The insert and vector were annealed, and the resulting plasmid was used to transform E. coli NEB5 $\alpha$ cells (New England Biolabs, Germany). Transformed colonies were screened by colony PCR for recombinant plasmids that were purified, verified by sequencing, and used for protein expression.

\section{Protein expression and purification}

Large-scale expression of ScTrl1 PNK/CPDase, ScTrl1 CPDase, and BfPNK/CPDase was performed in E. coli Rosetta(DE3) cells (Novagen, Germany) cultured in LB medium containing $100 \mu \mathrm{g} / \mathrm{ml}$ ampicillin and $34 \mu \mathrm{g} / \mathrm{ml}$ chloramphenicol. After reaching an $\mathrm{OD}_{600}$ of 0.5-0.6, expression was induced with $0.15 \mathrm{mM}$ isopropyl $\beta$-D-1 thiogalactopyranoside (IPTG) for $16 \mathrm{~h}$ at $+18{ }^{\circ} \mathrm{C}$. The cells were harvested by centrifugation and resuspended in lysis buffer (50 mM HEPES, pH 7.5, $200 \mathrm{mM} \mathrm{NaCl}$, $10 \mathrm{mM} \beta$-mercaptoethanol ( $\beta$-ME), $20 \mu \mathrm{g} / \mathrm{ml}$ DNase, Ambion RNase cocktail containing RNase A and RNase T1(Life Technologies, Germany), $5 \mathrm{mM} \mathrm{MgCl}_{2}$, and cOmplete mini EDTA-free protease inhibitors (Roche, Germany)). The suspension was incubated for $20 \mathrm{~min}$ at $+4{ }^{\circ} \mathrm{C}$ on a tube rotator. The cells were disrupted by sonication, and debris was removed by centrifugation at $35,000 \mathrm{~g}$ for $30 \mathrm{~min}$ at $+4{ }^{\circ} \mathrm{C}$. The supernatant was applied to a gravity-flow Ni-NTA column, pre-equilibrated with lysis buffer. The columns were rotated horizontally for $1 \mathrm{~h}$ to ensure binding of the protein to the matrix. The column was washed with lysis buffer containing $50 \mathrm{mM}$ imidazole, and bound protein was eluted with lysis buffer including $500 \mathrm{mM}$ imidazole. The eluted fractions were studied by SDS-PAGE, and the fractions containing the protein of expected size were pooled and dialyzed against the lysis buffer (without imidazole). The $\mathrm{N}$-terminal hexahistidine tag was cleaved using recombinant $3 \mathrm{C}$ protease at $+4{ }^{\circ} \mathrm{C}$ overnight. The cleaved protein was further purified by Ni-NTA affinity chromatography and dialyzed against the lysis buffer without imidazole. The dialyzed proteins were concentrated and applied either to a HiLoad 16/60 Superdex 200 preparative grade column (column volume: $120 \mathrm{ml}$; injection volume: $1 \mathrm{ml}$ ) or to a Superdex 75 10/300 GL analytical grade column (column volume: $24 \mathrm{ml}$; injection volume: $100 \mu \mathrm{l}$ ), pre-equilibrated with $50 \mathrm{mM}$ HEPES ( $\mathrm{pH} 7.5$ ), $200 \mathrm{mM} \mathrm{NaCl}, 10 \mathrm{mM} \beta$-ME. Equilibration, injection, and elution were all carried out at a flow rate of $1 \mathrm{ml} /$ min. The protein-containing peaks were analyzed by SDS-PAGE, and the fractions containing the proteins of interest were pooled, concentrated, flash-frozen, and stored at $-80{ }^{\circ} \mathrm{C}$. The identity of the purified proteins was verified by tryptic peptide mapping using mass spectrometry at the Biocenter Oulu Proteomics Core Facility.

Full-length mouse CNPase ( $\mathrm{MmCNPase}$, residues 20 420 of isoform 2), the N-terminal PNK domain ( $M m$ CNP_N, residues 20-180), and the C-terminal catalytic CPDase domain ( $M m C N P \_C$, residues 179-398) were purified using Ni-NTA chromatography, followed by His-tag cleavage using TEV protease, a second NiNTA step, and size exclusion chromatography (SEC), essentially as described before [30].

\section{Synchrotron radiation circular dichroism spectroscopy}

The folding of ScTrl1 PNK/CPDase, BfPNK/CPDase, and ScTrl1 CPDase was studied by SRCD spectroscopy on the UV-CD12 beamline at the ANKA Synchrotron. The proteins purified by SEC were dialyzed into a buffer compatible with SRCD analysis $(50 \mathrm{mM}$ potassium phosphate, $\mathrm{pH}$ 6.5). The range of protein concentrations used was between 3.5 and $5 \mathrm{mg} / \mathrm{ml}$. Three spectra were collected at a scan rate of $14 \mathrm{~nm} / \mathrm{min}$, in a demountable $13-\mu \mathrm{m} \mathrm{CaF}_{2}$ cuvette at a wavelength range between 260 and $170 \mathrm{~nm}$ at $1 \mathrm{~nm}$ intervals. A spectrum from the corresponding buffer was measured for all the samples and used for background correction. The data were processed with CDtool [35] and analyzed using Dichroweb [36].

\section{PNK activity assay}

The PNK activity of the N-terminal PNK domain of ScTrl1 PNK/CPDase and BfPNK/CPDase was assayed using the synthetic oligonucleotides ribo $A_{20}\left(A_{20}\right)$ and deoxy $A_{20}\left(\mathrm{dA}_{20}\right)$, and a mixture of the two $\left(\mathrm{A}_{20}+\right.$ $\left.\mathrm{dA}_{20}\right)$. T4 PNK and ScTrl1 CPDase were used as positive and negative controls, respectively. The reaction mixture contained $70 \mathrm{mM}$ Tris, $\mathrm{pH} 7.5,10 \mathrm{mM} \mathrm{MgCl}$, and $5 \mathrm{mM}$ DTT, $2 \mu \mathrm{g}$ of enzyme, and 100 pmol $\mathrm{A}_{20}$ or $\mathrm{dA}_{20}$ or both. 55 pmol of radioactively labelled $\left[\gamma^{32} \mathrm{P}\right]$ ATP were added to each reaction mixture, and the volume of the mixtures was adjusted to $40 \mu \mathrm{l}$ with diethylpyrocarbonate-treated water. The samples were incubated at $+37{ }^{\circ} \mathrm{C}$, and $8-\mu \mathrm{l}$ aliquots were removed at different time points $(1,15,30$, and $60 \mathrm{~min})$. Each sample was quenched with $8 \mu \mathrm{l}$ of $2 \mathrm{X}$ urea sample loading buffer (Invitrogen Novex) and heated at $+90{ }^{\circ} \mathrm{C}$ for $4 \mathrm{~min}$. The samples were analyzed by electrophoresis 
using a 15\% Mini-PROTEAN TBE-Urea gel (Bio-Rad), at $150 \mathrm{~V}$ for $85 \mathrm{~min}$, and visualized using PhosphorImager analysis.

\section{CPDase activity assay}

Kinetic measurements were carried out as previously described $[30,37]$. In this assay, CPDase hydrolyzes the phosphodiester bond in $\beta$-nicotinamide adenine dinucleotide $2^{\prime}, 3^{\prime}$-cyclic monophosphate $\left(2^{\prime}, 3^{\prime}\right.$-cNADP $\left.{ }^{+}\right)$, and the resulting nicotinamide adenine dinucleotide phosphate $\left(\mathrm{NADP}^{+}\right)$is reduced to NADPH by glucose6-phosphate dehydrogenase and used to transform glucose-6-phosphate to 6-phosphoglucanolactone. The quantity of NADPH formed during the coupled enzymatic reaction is a direct measure of CPDase activity [38].

The assay mixture contained $100 \mathrm{mM}$ MES, $\mathrm{pH}$ 6.0, $3 \mathrm{mM} \mathrm{MgCl} 2,5 \mathrm{mM}$ glucose-6-phosphate, and $0.6 \mathrm{U}$ glucose-6-phosphate dehydrogenase. $500 \mathrm{ng}$ of the purified enzyme was mixed with varying concentrations of the substrate, $2^{\prime}, 3^{\prime}-\mathrm{cNADP}^{+}(0,0.05,0.1,0.2,0.5$, and $1.0 \mathrm{mM}$ ), and NADPH production was measured spectrophotometrically at $340 \mathrm{~nm}$, using the absorption coefficient $6.22 \mathrm{~cm}^{-1} \mathrm{mM}^{-1}$. The measurements were carried out in triplicate at $+25{ }^{\circ} \mathrm{C}$ using 96-well flat-bottom transparent plates with the TECAN Infinite M200 fluorescence spectrophotometer and iControl software.

\section{Thermal stability assay}

Fluorescence-based thermal shift assays were carried out in triplicate, essentially as described [39]. Measurements were performed with a CFX96 RealTime PCR system (BioRad), using a 96-well thin-wall PCR plate. 1-5 $\mu \mathrm{g}$ of protein and 1-2 X SYPRO Orange dye were included in a total volume of $25 \mu \mathrm{l}$ per condition. The plate was sealed with optical-quality adhesive film (BioRad) and heated from $+25{ }^{\circ} \mathrm{C}$ to $+99{ }^{\circ} \mathrm{C}$ in $0.5{ }^{\circ} \mathrm{C}$ increments. A total of 80 different conditions, varying in $\mathrm{pH}$, salt type and concentration, and the presence of ligands, were screened. The fluorescence of SYPRO Orange was measured using excitation at $490 \mathrm{~nm}$ and emission at $575 \mathrm{~nm}$. The apparent thermal melting points $\left(\mathrm{T}_{\mathrm{m}}\right)$ were determined for each construct under all 80 conditions.

\section{Small-angle X-ray scattering}

SAXS measurements were carried out on the EMBL beamline X33 at DESY, Hamburg (Germany), the I911-4 SAXS beamline of MAX-Lab in Lund (Sweden), and the P12 BioSAXS beamline at PETRA-III, DESY, Hamburg. The ScTrl1 PNK/CPDase and BfPNK/CPDase eluted from SEC both as a dimer and as a monomer. These fractions were collected separately, concentrated, and used for SAXS measurements; only the data from the monomeric fraction were analyzed in detail, as dimerization was likely an artifact of non-specific disulphide formation. Sample concentrations were 1$10 \mathrm{mg} / \mathrm{ml}$. Monomeric BSA was measured first as a MW standard. Solvent scattering from the corresponding buffer was measured identically before and after each sample, and the average background scattering was subtracted. The data were analyzed with the ATSAS [40] suite, as described $[41,42]$. The data were processed using PRIMUS [43]. Distance distributions were calculated using GNOM [44], and $a b$ initio bead modeling was done with DAMMIF [45]. DAMAVER [46] was used for model averaging. GASBOR [47] was used for building chain-like $a b$ initio models, and MONSA [48] was used to assemble a 2-phase model of ScTrl1 PNK/CPDase, employing data from both ScTrl1 PNK/CPDase and ScTrl1 CPDase. The models were compared in PyMOL.

\section{Results and discussion}

\section{Protein expression and purification}

A total of nine expression clones including eight for different segments of yeast Trl1 and one for lancelet PNK/CPDase were prepared (Fig. 1). All constructs contain an $\mathrm{N}$-terminal hexahistidine tag followed by a $3 \mathrm{C}$ protease cleavage site and the corresponding PNK/ CPDase domain. The expression level of the different constructs was screened in three E. coli cell lines [BL21(DE3), BL21(DE3) CodonPlus RIPL, and Rosetta(DE3)] under different expression conditions, including various inducer concentrations and post-induction growth temperatures. The constructs encoding different regions of the Sc PNK domain did not show any expression in the three cell lines tested; the remaining five constructs could be expressed. The same pattern was observed previously for the yeast ScTrl1 PNK domain and the N-terminal domain of mouse CNPase $[16,30]$. The solubility of the proteins expressed in Rosetta (DE3) was remarkably high. Screening growth conditions post-induction revealed longer incubation at lower temperatures to be the optimal expression strategy. For large-scale production of ScTrl1 PNK/CPDase and $B f P N K / C P D a s e$, up to 81 of culture were used to obtain $\sim 5 \mathrm{mg}$ of protein, whereas $2 \mathrm{l}$ of culture was sufficient to achieve similar quantities of the $\mathrm{ScCPDase}$ domains.

The expressed proteins were initially purified by $\mathrm{Ni}$ NTA affinity chromatography and SEC (Additional file 2 \& Figs. 2 and 3). ScTrl1 PNK/CPDase and BfPNK/ CPDase eluted as double peaks with elution volumes corresponding to dimeric and monomeric forms. The fractions from each of the two peaks were collected separately, concentrated, and analyzed by SDS PAGE. Both peaks contained pure protein. The vertebrate homologue, mouse CNPase, exhibits similar oligomeric behaviour, and in this case, the N-terminal RNAbinding domain mediated dimerization [27]. The addition of either $10 \mathrm{mM} \beta$-ME or $5 \mathrm{mM}$ DTT in the lysis and purification buffers inhibited dimerization of 

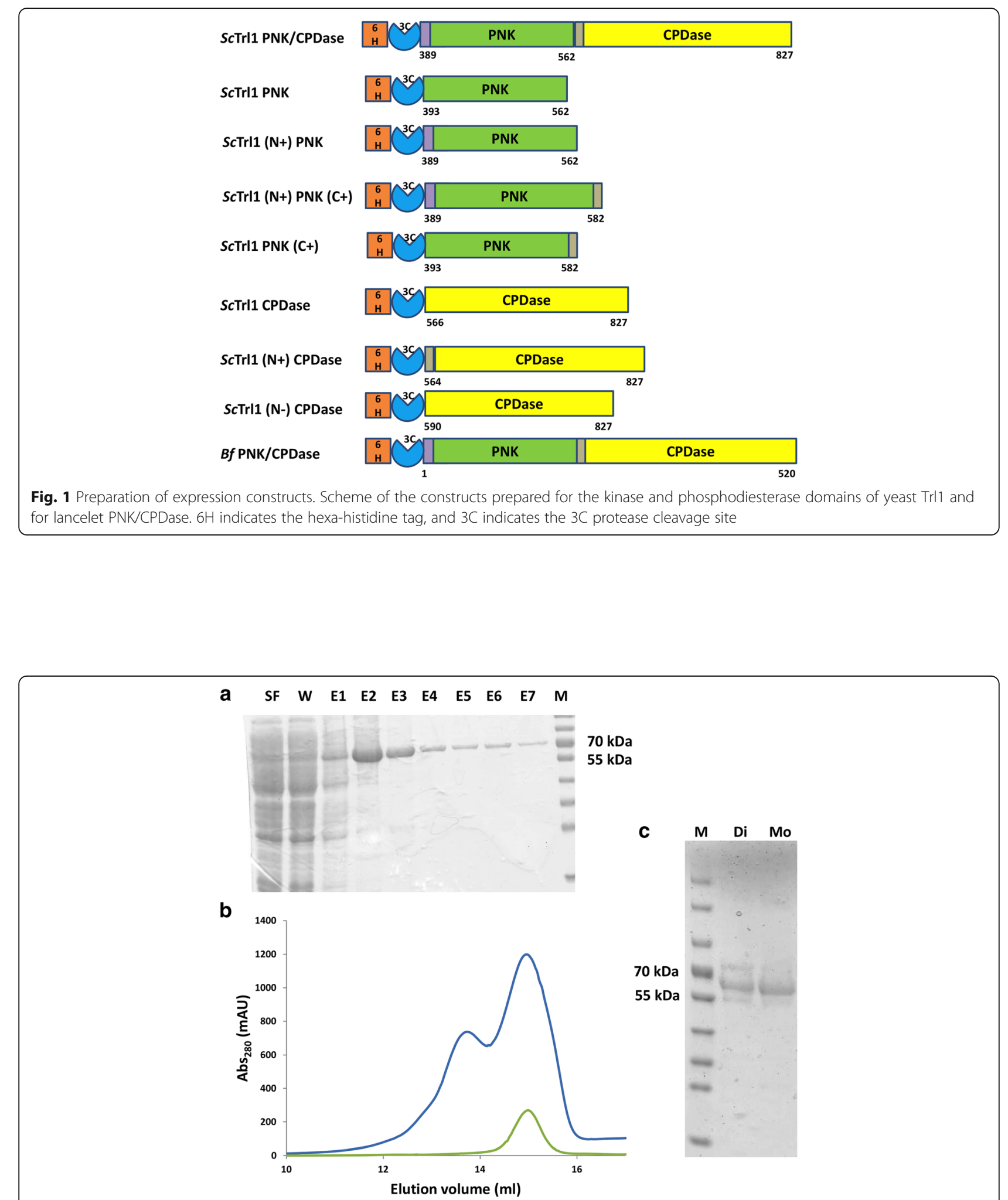

Fig. 2 Purification of BAPNK/CPDase. a SDS PAGE from a Ni-NTA purification of BAPNK/CPDase. SF: supernatant flow-through, W: wash, E1-E7: fractions eluted with $500 \mathrm{mM}$ imidazole, M: marker. The calculated size of the protein was $60.3 \mathrm{kDa}$. b Superdex75 SEC profile of BAPNK/CPDase. The blue curve shows a mixture of monomer and dimer in the absence of any reducing agent, and the green curve shows the monomer in the presence of $5 \mathrm{mM} \beta$ ME. The single monomeric peak (green) indicates that the dimer formation is inhibited by $\beta$-ME. c SDS-PAGE from a SEC purification of BAPNK/CPDase in the absence of a reducing agent. M: marker, Di: BAPNK/CPDase dimer, Mo: BAPNK/CPDase monomer 

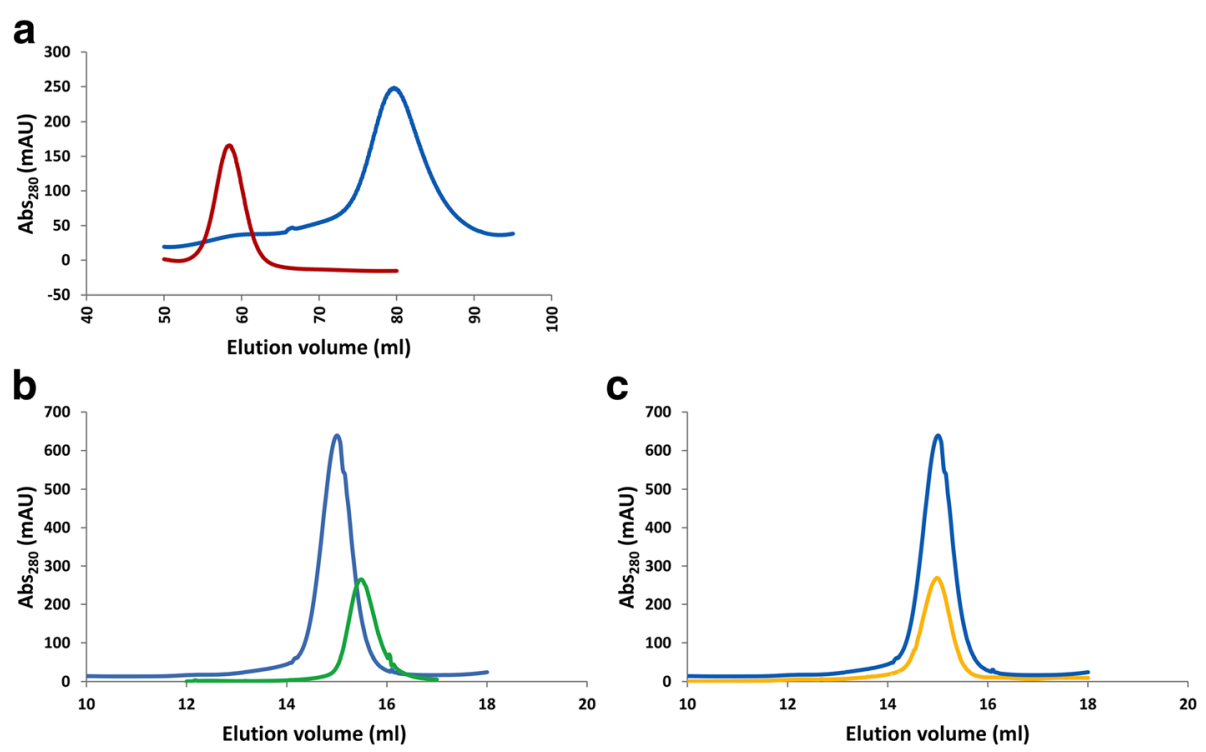

Fig. 3 Yeast PNK/CPDase and CPDase purified by size exclusion chromatography. a Superdex200 SEC profile of SCTrl1 PNKVCPDase monomer (dark red) and ScTrl1 CPDase (blue). b Superdex75 SEC profile of ScTrl1 CPDase (blue) and ScTrl1 (N-) CPDase (green). c Superdex75 SEC profile of ScTrl1 CPDase (blue) and ScTrl1 ( $\mathrm{N}+$ ) CPDase (orange). The CPDase proteins elute around the same elution volume and exist as monomers

ScTrl1 PNK/CPDase and BfPNK/CPDase, indicating that the dimers are linked by a disulphide. Most likely the physiologically relevant form of each protein is monomeric.

The elution profiles of the CPDase constructs contained a single symmetric peak (Fig. 3b, c), and no oligomerization or RNA binding was detected. The absence of dimerization and RNA binding in the CPDase domain suggest that these processes require the $\mathrm{N}$-terminal PNK domain. Similarly, the N-terminal PNK-like domain of mouse CNPase is involved not only in dimerization, but also in RNA binding [27]. The purified proteins were easily degraded upon storage at $+4{ }^{\circ} \mathrm{C}$. Hence, immediate flash-freezing and storage of the purified proteins in the freezer was essential. Since the stability of $S c \operatorname{Tr} 1$ CPDase was found to be comparatively better than the other two CPDase protein variants, it was used in further biophysical and biochemical experiments.

\section{PNK/CPDase enzymes interact with Eschericia coli nucleic acids}

During the purification of ScTrl1 PNK/CPDase and $B f P N K / C P D a s e$, a large peak was always present right after the void volume of the SEC column (Fig. 4a). Since the absorbance at $260 \mathrm{~nm}$ was very high for this peak, co-purification of a nucleic acid, possibly RNA, from the expression host, was suspected. To identify the nucleic acid bound to the protein, the fractions eluted around

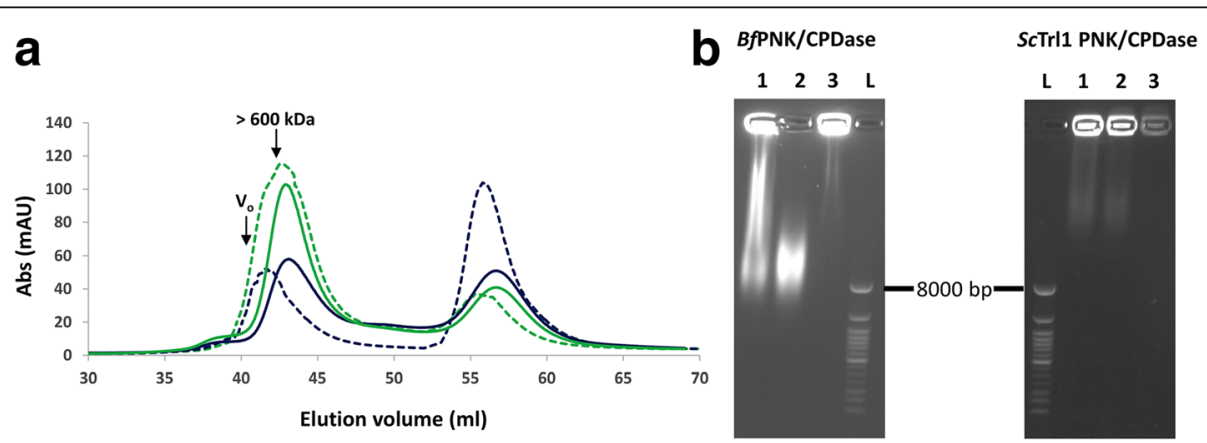

Fig. 4 PNK/CPDase interacts with E. coli RNA. a Superdex 200 SEC profile of SCTrl1 PNK/CPDase (continuous lines) and BAPNK/CPDase (dashed lines). The peaks close to the void volume with $\mathrm{A}_{260}$ (green) higher than $\mathrm{A}_{280}$ (blue) indicate the presence of a nucleic acid. $V_{0}$ : column void volume. b Agarose gels of BAPNK/CPDase and SCTrl1 PNK/CPDase. L: DNA ladder, 1: The protein-nucleic acid complex eluted near the void volume from SEC, 2: DNase-treated protein-nucleic acid complex, 3: RNase-treated protein-nucleic acid complex. RNase degrades the nucleic acid, confirming that the copurified molecule is, in fact, RNA 
the void volume in SEC were treated with DNase and RNase A. Agarose gels of nuclease-treated samples show that the bright smear in the larger elution fraction and in the same fraction treated with DNase was not found in the presence of RNase A (Fig. 4b). This finding confirms that the co-purified nucleic acid impurity contained RNA. In addition, DNA was present in the $B f P N K / C P D a s e$ sample. When a combination of RNase $A$ and RNase T1 was added in the lysis buffer during subsequent purification, the $\mathrm{A}_{260}$ peak height remarkably decreased, additionally proving that the contaminant was RNA.

The behaviour of PNK/CPDase proteins in these assays was highly similar to the uracil-DNA degrading factor and mouse CNPase [27, 49]. CNPase has also been shown to interact with RNA in vitro and co-purify with poly(A) ${ }^{+}$RNA; the catalytic domain of CNPase has been shown to be sufficient for binding with single stranded RNA homopolymers [50,51]. However, a pulldown assay with mouse CNPase and poly(A)-sepharose indicated that the N-terminal domain binds RNA more efficiently than the C-terminal domain [27]. The absence of the peak closely following the void volume during SEC purification of the yeast CPDase domain indicates the $\mathrm{N}$-terminal PNK domain is required for RNA binding, at least in the case of $E$. coli RNA.

\section{Bacterially expressed PNK/CPDase and CPDase proteins are folded}

The folding state of the purified proteins was analyzed by SRCD spectroscopy. Visual inspection of the SRCD spectra indicates that the PNK/CPDase and CPDase proteins were folded, containing a mixture of $\alpha$ helix and $\beta$ strand. SRCD spectra from ScTrl1 PNK/CPDase and BfPNK/CPDase show a similar shape (Fig. 5a), indicating the presence of similar amounts of regular secondary structure. The spectra also indicate that the N-terminal truncation of $S c \operatorname{Trl} 1$ CPDase is less folded than ScTrl1
CPDase (Fig. 5b). The latter is indicative of sub-optimal folding of the truncated construct.

\section{Ligand binding improves thermal stability}

Since the stability of the monomers of both ScTrl1 PNK/ CPDase and BfPNK/CPDase during and after purification was initially low, the identification of a stabilizing buffer condition was necessary. A thermal stability assay was used to identify suitable buffer conditions that would offer increased stability of the protein. The melting curves and corresponding $\mathrm{T}_{\mathrm{m}}$ values of $S c \mathrm{Tr} 11 \mathrm{PNK} / \mathrm{CPD}$ ase, $S c \operatorname{Trl} 1$ CPDase, and BfPNK/CPDase indicate that all three proteins are most stable around $\mathrm{pH} 7.5$. The combination of $50 \mathrm{mM}$ HEPES, $\mathrm{pH} 7.5$, and $150 \mathrm{mM} \mathrm{NaCl}$ was identified as an optimal stabilizing buffer.

To analyze the effect of ligands on the thermal stability of the proteins, two known substrates of CPDase, 2',3'cCMP and $2^{\prime}, 3^{\prime}-\mathrm{cNADP}^{+}$, and the product $\mathrm{NADP}^{+}$were included in the screen. The $T_{m}$ values indicate that $2^{\prime}, 3^{\prime}-$ $\mathrm{cNADP}^{+}$improves the thermal stability of all three proteins tested (Fig. 6, Table 1); however, 2',3'-cCMP and $\mathrm{NADP}^{+}$do not influence the stability of any of them. The highest melting points obtained for ScTrl1 PNK/CPDase and $B f \mathrm{PNK} / \mathrm{CPD}$ ase were $+63{ }^{\circ} \mathrm{C}$ and $+48^{\circ} \mathrm{C}$, respectively, both in the presence of $2^{\prime}, 3^{\prime}-\mathrm{CNADP}^{+}$. ScTrl1 CPDase was found to be the most stable among the proteins tested, with a melting temperature of $+72{ }^{\circ} \mathrm{C}$ in a buffer containing $50 \mathrm{mM}$ HEPES, pH 7.5, $150 \mathrm{mM} \mathrm{NaCl}$, and $1 \mathrm{mM}^{2}, 3^{\prime}-\mathrm{CNADP}^{+}$. Mouse CNPase is more stable at pH 5.5 with higher salt than at neutral $\mathrm{pH}$ with lower salt, which stabilizes the yeast and lancelet proteins [30]. The thermal stability of $S c \operatorname{Trl} 1$ CPDase is also higher than that of the mouse CNPase catalytic domain and its mutated variants $[28,29]$.

\section{PNK/CPDase enzymes possess polynucleotide kinase activity}

The assay to test the PNK activity of the purified $S c$ Trl1 PNK/CPDase and BfPNK/CPDase involves transfer of
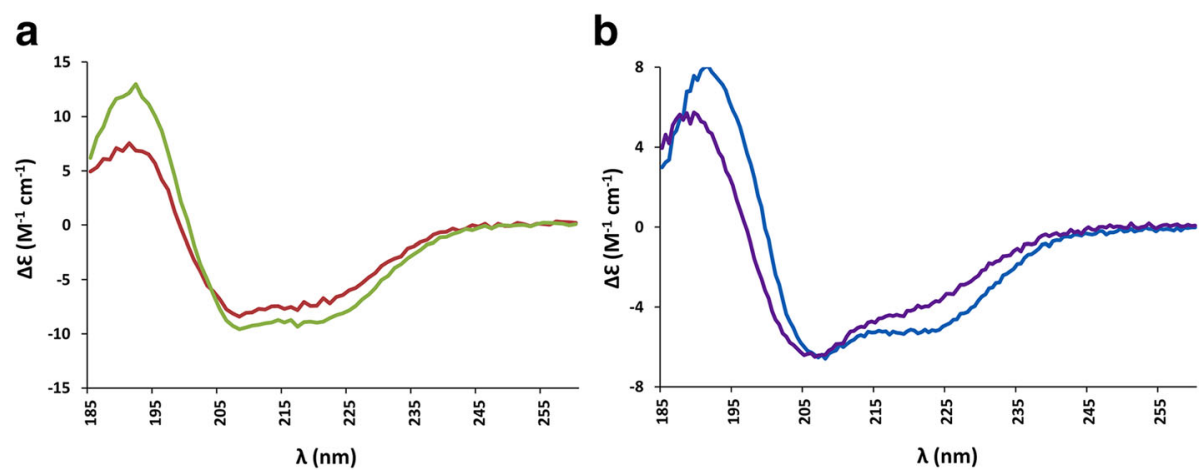

Fig. 5 SRCD spectra of purified proteins. a SCTrl1 PNK/CPDase (red) and BPPNK/CPDase (green). b ScTrl1 CPDase (blue) and ScTrl1 (N-) CPDase (purple). The SRCD spectra indicate that all tested proteins are folded 

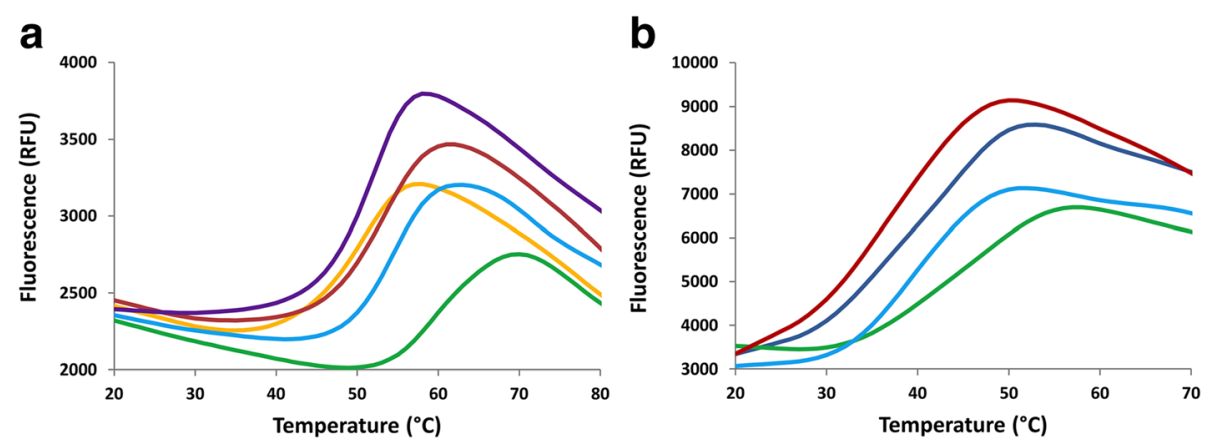

Fig. 6 Thermal stability assay. a A selection of thermal shift assay melting curves for ScTrl1 PNK/CPDase. Colour code: Violet - $50 \mathrm{mM}$ citric acid, pH 5.5, 150 mM NaCl; Dark red - 50 mM MOPS, pH 6.5, 500 mM NaCl; Orange - 50 mM imidazole, pH 8.0, 150 mM NaCl; Light blue - 50 mM HEPES, pH 7.5, 150 mM NaCl; Green - 50 mM HEPES, pH 7.5, 150 mM NaCl, 1 mM 2',3'-cNADP'. b A selection of thermal shift assay melting curves for Bf PNK/CPDase. Colour code: Dark red - 50 mM MOPS, pH 6.5, 500 mM NaCl; Blue - 50 mM MES, pH 7.0, 150 mM NaCl; Light blue - 50 mM HEPES, pH $7.5150 \mathrm{mM} \mathrm{NaCl}$; Green - 50 mM HEPES, pH 7.5, $150 \mathrm{mM} \mathrm{NaCl}, 1$ mM 2',3'-cNADP ${ }^{+}$. A clear increase in the melting temperature can be observed, induced by buffer conditions with pH 7.5, low salt concentration, and 2',3'-cNADP ${ }^{+}$

the ${ }^{32} \mathrm{P}$-labelled terminal phosphate from $\left[\gamma^{32} \mathrm{P}\right]$ ATP to a 20 -mer $5^{\prime}-\mathrm{OH}$ synthetic RNA $\left(\mathrm{A}_{20}\right)$ or DNA oligonucleotide $\left(\mathrm{dA}_{20}\right)$. To study the substrate preferences of the enzymes on RNA and DNA oligonucleotide substrates, the transfer of the radiolabelled phosphate to a mixture of $\mathrm{A}_{20}$ and $\mathrm{dA}_{20}$ was also analyzed. The timedependent transfer of the phosphate from $\left[\gamma^{32} \mathrm{P}\right]$ ATP to the $5^{\prime}-\mathrm{OH}$ groups of the synthetic oligonucleotides indicates that both ScTrl1 PNK/CPDase and BfPNK/ CPDase possess PNK activity (Fig. 7a-b). ScTrl1 CPDase did not catalyze phosphoryl transfer (Fig. 7c). The results indicate that ScTrl1 PNK/CPDase prefers $\mathrm{A}_{20}$ (Fig. 7a) and $B f$ PNK/CPDase strongly prefers $\mathrm{dA}_{20}$ (Fig. 7b).

BfPNK/CPDase was previously shown to prefer DNA over RNA, whereas another lancelet PNK, Bf Clp1, was reported to act exclusively on RNA [8]. This finding suggested a possible role for BfPNK/ CPDase in DNA repair. The fact that we saw DNA co-purifying with $B f \mathrm{PNK} / \mathrm{CPD}$ ase and that the enzyme preferred the DNA substrate in the PNK assay support this hypothesis. The decrease in size of the labelled $\mathrm{dA}_{20}$ oligonucleotide during the assay could be related to an unknown activity of BfPNK/CPDase towards DNA. The homologue of yeast and lancelet PNK/CPDase, mammalian CNPase, was found to rescue a yeast strain with an inactivating mutation in the CPDase domain of yeast tRNA ligase, but not a strain with a mutated kinase domain [52]. Thus, it appears that the N-terminal PNK-like domain of vertebrate CNPase is not functionally a PNK. This is supported by our results from the PNK activity assays. $M m C N P a s e$, as well as its two domains separately, were inactive, while the homologous yeast and lancelet PNK/CPDase proteins were active (Fig. 7a, b, Additional file 3). This finding also supports the hypothesis that vertebrates might employ the $5^{\prime}$-P RNA ligation pathway only as an alternate to 3 '-P RNA

Table 1 Comparison of $T_{m}$ values for ScTrl1 PNK/CPDase, ScTrl1 CPDase, and BfPNK/CPDase. The highest $T_{m}$ values are indicated in bold

\begin{tabular}{|c|c|c|}
\hline Protein & Buffer condition & $\mathrm{T}_{\mathrm{m}}\left({ }^{\circ} \mathrm{C}\right)$ \\
\hline \multirow[t]{3}{*}{ ScTrl1 PNK/CPDase } & $50 \mathrm{mM}$ HEPES, pH 7.5, $150 \mathrm{mM} \mathrm{NaCl}$ & 55 \\
\hline & 50 mM imidazole, pH 8.0, 150 mM NaCl & 50 \\
\hline & 50 mM HEPES, pH 7.5, 150 mM NaCl, 1 mM 2',3'-cNADP ${ }^{+}$ & 63 \\
\hline \multirow[t]{3}{*}{ ScTrl1 CPDase } & 50 mM HEPES, pH 7.5, 150 mM NaCl & 58 \\
\hline & 50 mM imidazole, pH 8.0, 150 mM NaCl & 55 \\
\hline & 50 mM HEPES, pH 7.5, 150 mM NaCl, 1 mM 2',3'-CNADP ${ }^{+}$ & 72 \\
\hline \multirow[t]{3}{*}{ BfPNK/CPDase } & 50 mM HEPES, pH 7.5, 150 mM NaCl & 43 \\
\hline & 50 mM MES, pH 7.0, 500150 mM NaCl & 43 \\
\hline & 50 mM HEPES, pH 7.5, 150 mM NaCl, 1 mM 2',3'-cNADP ${ }^{+}$ & 48 \\
\hline
\end{tabular}




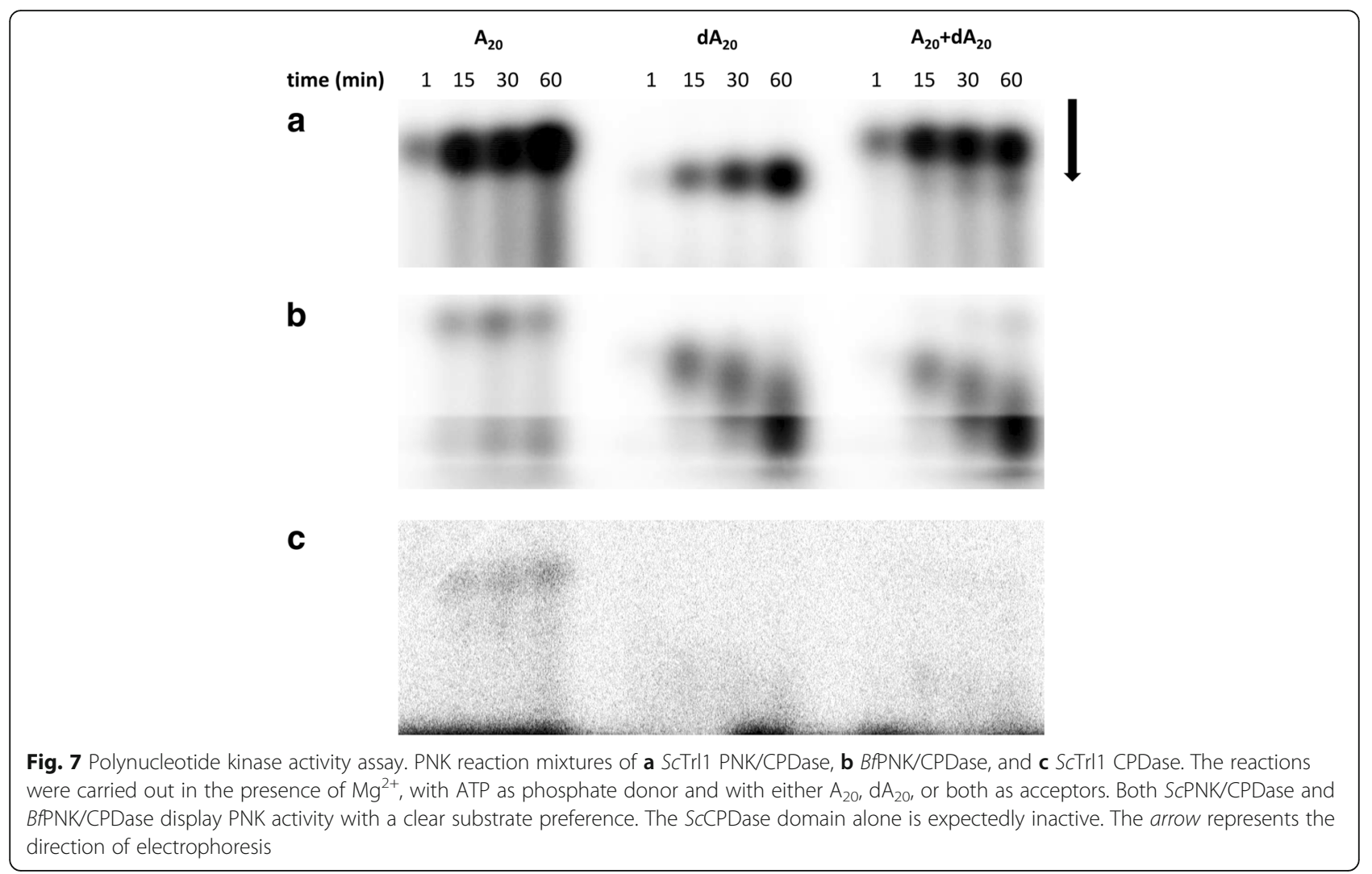

ligation and, thus, require only the exclusive polynucleotide kinase (Clp1) for the healing reaction, and not the N-terminal PNK-like domain of CNPase.

\section{PNK/CPDase and CPDase enzymes possess cyclic} nucleotide phosphodiesterase activity

The CPDase activity of ScTrl1 PNK/CPDase, BfPNK/ CPDase, and ScTrl1 CPDase was assayed using 2',3'$\mathrm{cNADP}^{+}$as substrate in a coupled enzyme assay [37, 38]. The results indicate that all tested constructs are active in the phosphodiesterase reaction (Table 2) and that the activity is comparable to that of the different constructs of mouse and rat CNPase. Thus, CPDase activity is a common denominator for $2 \mathrm{H}$ enzymes across kingdoms of life.

\section{PNK/CPDase enzymes are elongated in solution}

SAXS measurements were carried out to determine lowresolution structural models of the proteins and to analyze their oligomeric state in solution. Although SAXS data were collected for all the five expressed constructs, only three of them, the ScTrl1 PNK/CPDase, the

Table 2 Kinetic parameters for the CPDase activity of different constructs on 2', $3^{\prime}$-CNADP ${ }^{+}$

\begin{tabular}{llcl}
\hline Protein & $\mathrm{K}_{\mathrm{m}}(\mu \mathrm{M})$ & $\mathrm{k}_{\text {cat }}\left(\mathrm{s}^{-1}\right)$ & $\mathrm{k}_{\text {cat }} / \mathrm{K}_{\mathrm{m}}\left(\mu \mathrm{M}^{-1} \mathrm{~s}^{-1}\right)$ \\
\hline Enzymes used in the study & & & 1.15 \\
BfPNK/CPDase (500 ng) & $440 \pm 50 \pm 20$ & 0.75 \\
ScTrl1 PNK/CPDase (500 ng) & $420 \pm 35$ & $317 \pm 15$ & 1.16 \\
ScTrl1 CPDase (500 ng) & $237 \pm 27$ & $275 \pm 18$ & \\
Homologous enzymes & & & $270 \pm 10$ \\
MmCNPase - full length (500 ng) [30] & $193 \pm 26$ & $570 \pm 19$ & 1.40 \\
MmCNPase - catalytic domain (500 ng) [30] & $445 \pm 41$ & $836 \pm 11$ & 3.2 \\
Rat CNPase - full length [37] & $263 \pm 12$ & $1690 \pm 39$ & 5.7 \\
Rat CNPase - catalytic fragment [37] & $295 \pm 22$ & \\
\hline
\end{tabular}


ScTrl1 CPDase, and the BfPNK/CPDase, yielded goodquality SAXS data, and only these were used for further processing and modeling. The best datasets were collected between 3 and $4 \mathrm{mg} / \mathrm{ml}$, with a strong scattering signal and without significant interparticle effects, as shown by the linearity of the Guinier plot (Fig. 8a, b).

The monomeric ScTrl1 PNK/CPDase and BfPNK/ CPDase display similarly elongated conformations, with BfPNK/CPDase being more extended (Fig. 8a, e, f and Table 3). The estimated Porod volume is in agreement with a monomeric form of both proteins. The $p(\mathrm{r})$ profile displays a single peak with shoulders for both yeast and lancelet PNK/CPDase proteins (Fig. 8c), indicating an asymmetric scattering particle, possibly containing two domains bridged by a flexible linker. Dimensionless Kratky plots (Fig. 8d) further show that BfPNK/CPDase is the most flexible of the studied samples, in line with its relatively large volume-to-mass ratio (Table 3).

The 3D models for both PNK/CPDases are consistent with an arrangement, where the two domains form an elongated assembly. The model suggests that the active sites of the PNK domain and CPDase domain are accessible and not being blocked by the neighbouring domain. An open active site facilitates substrate binding without the need for large conformational changes. If the domains would cover each other more extensively, the shape of the molecule would be more globular.

The solution structure of full-length mouse CNPase is similar to that of the monomeric ScTrl1 PNK/CPDase and $B f P N K / C P D a s e$ [28], although somewhat more compact, reflecting the presence of large flexible insertions in the yeast and lancelet enzymes. Mouse CNPase is a monomer with an elongated conformation in solution [28]. Although the molecular masses of monomeric ScTrl1 PNK/CPDase [50.52 kDa] and monomeric mouse CNPase [44.8 kDa] are close to each other, the $D_{\max }$ and $R_{g}$ values are comparatively higher for the ScTrl1 PNK/CPDase (Table 3). This could be due to the presence of a flexible linker region between the $\mathrm{N}$-terminal $\mathrm{PNK}$ and $\mathrm{C}$-terminal CPDase domains in ScTrl1 PNK/CPDase: this segment is absent in mouse CNPase (Fig. 9a). Based on SAXS data and molecular modelling, the C-terminal membraneanchoring tail of the mouse CNPase lies in the middle region of the molecule, enabling the association of the active site to the vicinity of the lipid bilayer [28].

\section{CPDase is compact in solution}

The molecular size determined from the SAXS profile of ScTrl1 CPDase indicates that the molecule is more compact in solution than $S c \operatorname{Trl} 1$ PNK/CPDase and exists as a monomer (Fig. 8a, c, d, f \& g, Table 3). Molecular mass
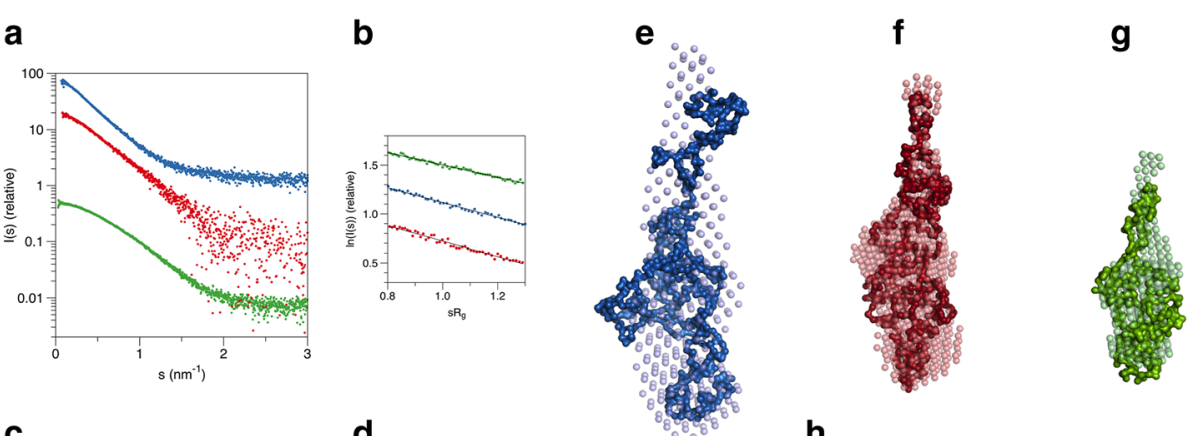

C

d

h
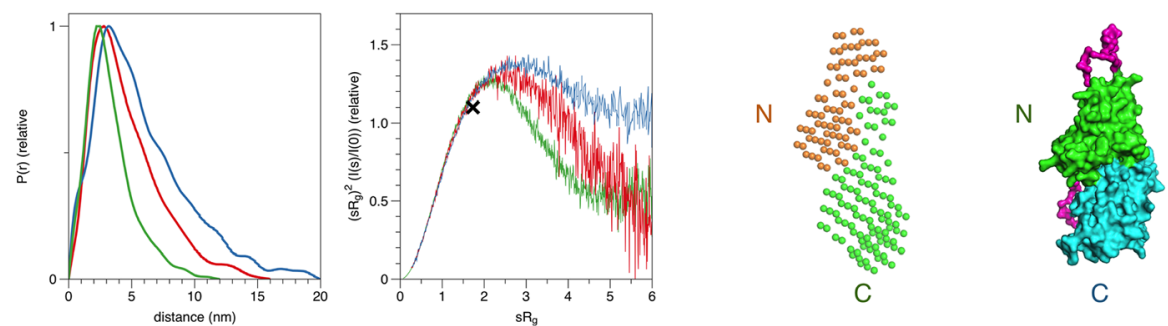

Fig. 8 SAXS analysis of Bf and SCTrl1 PNK/CPDases. a Scattering curves from monomeric Bf (blue) and ScTrl1 (red) PNK/CPDases and the ScTrl1 CPDase domain (green). The curves have been displaced for clarity. $\mathbf{b}$ Guinier plots for the samples in (A), plotted between $0.8<s R_{g}<1.3$. The curves have been moved in the y dimension for clarity. c Distance distribution functions for the samples shown in (A). $\mathbf{d}$ Dimensionless Kratky plots. The cross marks the expected peak position for a folded globular protein $(x=1.732, y=1.1)$. BAPNK/CPDase is most flexible of the proteins. e-g Ab initio 3D models for BfPNK/CPDase, SCTrl1 PNK/CPDase, and the SCTrl1 CPDase domain, respectively. The DAMMIF bead model is shown by spheres and the GASBOR chain-like model as a surface in each panel. $\mathbf{h}$ Comparison of the 2-phase MONSA model of ScTrl1 PNKVCPDase (left) with the earlier published SAXS structure of full-length MmCNPase (right) [28]. The positions of the N-terminal PNK domain and the C-terminal CPDase domain are indicated for both proteins. See Table 3 for the $\mathrm{chi}^{2}$ values corresponding to the fit between the raw data and the models 
Table 3 Structural parameters derived from experimental SAXS data and comparison to known parameters of mouse CNPase

\begin{tabular}{|c|c|c|c|c|c|}
\hline Protein & ScTrl1 PNK/CPDase & BfPNK/CPDase & ScTrl1 CPDase & MmCNPase [28] & $\begin{array}{l}\text { MmCNPase catalytic } \\
\text { domain [27] }\end{array}$ \\
\hline$D_{\max }(\mathrm{nm})$ & 11.6 & 14.3 & 8.5 & 8.8 & 7.1 \\
\hline Guinier $R_{g}(\mathrm{~nm})$ & 3.37 & 4.16 & 2.48 & 2.6 & 2.13 \\
\hline Real-space $R_{g}(\mathrm{~nm})$ & 3.79 & 4.83 & 2.69 & - & - \\
\hline$V_{p}\left(n m^{3}\right)$ & 78.6 & 137.7 & 50.1 & - & 44.4 \\
\hline $\begin{array}{l}\text { Ab initio } V\left(\mathrm{~nm}^{3}\right) \text { /estimated } \\
\text { MW of globular particle }(\mathrm{kDa})\end{array}$ & $106 / 78.7$ & $212 / 157.4$ & $30.5 / 22.6$ & - & - \\
\hline Monomeric MW (kDa) & 52.7 & 60.3 & 32.2 & 42 & 24 \\
\hline $\begin{array}{l}\mathrm{S}_{\min } / \mathrm{s}_{\max }\left(\mathrm{nm}^{-1}\right) \text { bead-based } \\
\text { modeling }\end{array}$ & $0.09-2.52$ & $0.12-1.31$ & $0.08-3.72$ & - & - \\
\hline $\begin{array}{l}\mathrm{s}_{\min } / \mathrm{s}_{\max }\left(\mathrm{nm}^{-1}\right) \text { chain-based } \\
\text { modeling }\end{array}$ & $0.09-5.0$ & $0.12-2.8$ & $0.08-3.72$ & - & - \\
\hline $\mathrm{Chi}^{2}$ & $\begin{array}{l}1.0 \text { (DAMMIF), } \\
0.7 \text { (GASBOR), } \\
1.3 \text { (MONSA) }\end{array}$ & $\begin{array}{l}1.0 \text { (DAMMIF), } \\
1.0 \text { (GASBOR) }\end{array}$ & $\begin{array}{l}0.6 \text { (DAMMIF), } \\
0.7 \text { (GASBOR), } \\
1.2 \text { (MONSA) }\end{array}$ & - & - \\
\hline
\end{tabular}

determination shows the presence of a monomer. The Porod volume is also in line with the presence of monomeric ScTrl1 CPDase. The SAXS model shows the presence of an extension presumably in the $\mathrm{N}$ terminus of the protein; this tail possibly arises from the interdomain linker at the $\mathrm{N}$ terminus of the construct, suggesting the requirement for a shorter construct of the protein without the $\mathrm{N}$ terminal insertion to facilitate crystallization.

The solution structure of ScTrl1 CPDase resembles that of the catalytic domain of mouse CNPase [27]. The mouse CNPase catalytic domain is also monomeric in solution. Both ScTrl1 CPDase and the catalytic domain of mouse CNPase adopt an elongated conformation possibly due to the opening of the active-site cleft, as found in the NMR structure of rat CNPase catalytic domain $[25,27]$. The mouse CNPase catalytic domain displays a more compact structure in the presence of citrate and the ligand also reduces aggregation of the protein [27]. It has been suggested that the overall solution conformation of fully active CNPase might be more open than that seen in the crystal structures, in which the enzyme is bound to citrate and sulphate [27]. Different lengths of the mouse CNPase catalytic domain have been studied by SAXS [27]. The presence of a C-terminal tail does not alter the conformation of the catalytic domain in solution, whereas $\mathrm{N}$-terminally extended CNPase catalytic domain has a higher radius of gyration. Both $\mathrm{N}$ - and C-terminally extended protein is remarkably more elongated [27]. The symmetric peak of the $p(\mathrm{r})$ for ScTrl1 CPDase shows that the protein, similarly to the mouse CNPase catalytic domain, is more compact than the protein variants that also contain the $\mathrm{N}$-terminal domain (Fig. 8c).

The solution shapes and behaviour of the PNK/ CPDases and the CPDase are in many aspects comparable to those of the full-length mouse CNPase and its catalytic domain, respectively. The differences are likely caused by the relatively large insertions compared to CNPase: the yeast enzyme has a long insertion between the PNK and CPDase domains, while the lancelet enzyme has insertions in two loop regions of the CPDase domain (Fig. 9a, b). The SAXS model of full-length mouse CNPase indicates that the N-terminal PNK-like and the $\mathrm{C}$-terminal phosphodiesterase domains form an elongated assembly [28], and as shown here, the same is true for the yeast and lancelet enzymes. The biphasic model built for the yeast enzyme (Fig. 8h) compares well to the mouse CNPase solution structure. Thus, the domain arrangements of the yeast and lancelet PNK/ CPDase in solution resemble that of CNPase. An open elongated conformation of the full-length protein could be crucial for substrate binding [28]. Superposition of a homology model of the CPDase domain of BfPNK/ CPDase and the catalytic domain of $M m$ CNPase shows that the active site consisting of the $2 \mathrm{H}$ motifs is structurally conserved $[27,53]$ (Fig. 9b). The homology model of the lancelet CPDase domain contains a symmetrical bilobed tertiary structure, which is similar to the crystal structures of the catalytic domain of mouse and human CNPase [26-29]. The inserted loops within the CPDase domain of BfPNK/CPDase (Fig. 9b) were also the most flexible in the recently-determined structure of a bacterial $2 H$ phosphoesterase, LigT from $E$. coli [51].

Comparison of the SAXS models of ScTrl1 PNK/ CPDase, BfPNK/CPDase, and ScTrl1 CPDase with the SAXS structural parameters of the homologous mouse CNPase indicates that the structural and hydrodynamic properties of the different constructs can be explained by the presence of sequence insertions in the yeast and lancelet enzymes. A structural model of the PNK/ CPDase proteins (Fig. 9c) can be proposed based on the 

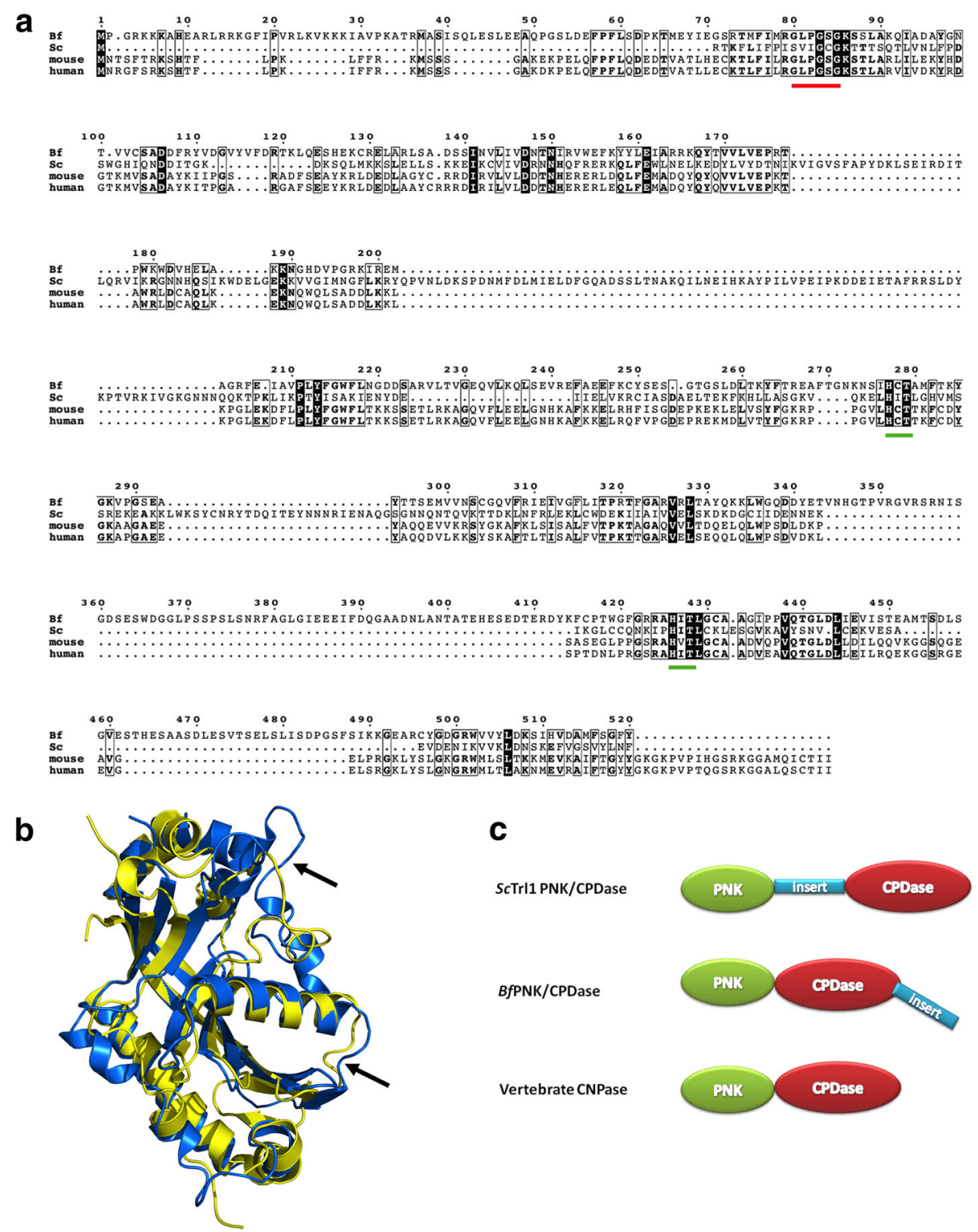

Fig. 9 Domain arrangement of PNK/CPDase proteins. a Multiple sequence alignment using T-Coffee [54]. Aligned sequences of SCTrl1 PNK/CPDase (SC), BAPNK/CPDase (Bf), MmCNPase (mouse), and HsCNPase (human). The N-terminal P-loop motif and two C-terminal H-x-(T/S)-x motifs are underlined in red and green, respectively. $\mathbf{b}$ Superposition of the homology model of the CPDase domain of BAPNK/CPDase (blue), generated using Phyre ${ }^{2}$, and the crystal structure of the catalytic domain of MmCNPase (yellow) [PDB ID: 2YDB] [27, 53]. The black arrows point to the locations of flexible loops in the homology model of the CPDase domain of BAPNK/CPDase (blue). c The overall three-dimensional shapes of PNK/CPDase proteins determined in this study can be used to propose a structural arrangement of the domains

determined 3-dimensional shapes. Yeast PNK/CPDase exhibits an elongated conformation with the presence of a possibly flexible region between the N-terminal PNK and C-terminal CPDase domains. Removal of the flexible region, which is not present in mouse CNPase, might aid in crystallization of the domains separately. The model also indicates that the two loop insertions in the CPDase domain in lancelet PNK/CPDase result in an even more elongated molecule, and these long loops point away from the PNK domain at the other end of the molecule. It is possible that BfPNK/CPDase also has a flexible region at its $\mathrm{N}$ terminus.

\section{Conclusions}

The open elongated conformation of the PNK/CPDases might play a role in RNA substrate binding; however, this needs to be confirmed by high-resolution structures of the enzymes with bound substrates. Based on 
currently available structural data, we can conclude that both enzymes display structural similarities to other members of the $2 \mathrm{H}$-phosphoesterase family - not only at the level of conserved sequence motifs, but also in their respective domain arrangements. The yeast and lancelet healing enzymes possess both PNK and CPDase activities, whereas the mouse CNPase, which also binds RNA, has no PNK activity. This suggests a loss of function at the CNPase N-terminal PNK-like domain over the course of evolution. On the other hand, BfPNK/ CPDase may have a unique substrate specificity within the family with respect to its PNK activity. Thus, our results on the structure and function of tRNA healing enzymes from yeast and lancelet provide evidence supporting the evolution of vertebrate CNPase from functional tRNA healing enzymes.

\section{Additional files}

Additional file 1: Table S1. Primers used for PCR amplification of target DNA fragments. (PDF $54 \mathrm{~kb}$ )

Additional file 2: Figure S1. The yeast PNK/CPDase and CPDase proteins purified by Ni-NTA affinity chromatography. A) SDS-PAGE from a Ni-NTA purification of SCTrl1 PNK/CPDase. M: marker, E1-E8: fractions eluted with $500 \mathrm{mM}$ imidazole. The calculated size of the protein was $52.7 \mathrm{kDa}$. B) SDSPAGE from Ni-NTA purifications of SCTrl1 CPDase and ScTrl1 (N+) CPDase. M: marker, SF1 and W1 are supernatant and wash flow-through samples from the purification of SCTrl1 CPDase, E1-E5: SCTrl1 CPDase fractions eluted with $500 \mathrm{mM}$ imidazole. The calculated size of the protein was $32.2 \mathrm{kDa}$. SF2 and W2 are supernatant and wash flow-through samples from the purification of ScTrl1 (N+) CPDase, E6-E10: ScTrl1 (N+) CPDase fractions eluted with $500 \mathrm{mM}$ imidazole. The calculated size of the protein was $32.4 \mathrm{kDa}$. C) SDS PAGE from a Ni-NTA purification of SCTrl1 (N-) CPDase. SF: supernatant flowthrough, W: wash flow-through, E1-E10: fractions eluted with $500 \mathrm{mM}$ imidazole, M: marker. The calculated size of the protein was $29.6 \mathrm{kDa}$. (PDF $220 \mathrm{~kb}$ )

Additional file 3: Figure S2. Polynucleotide kinase activity assay. PNK reaction mixtures of A) T4 PNK, B) MmCNPase C) MmCNP_N and D) MmCNP C. The reactions were carried out in the presence of $\mathrm{Mg}^{2+}$, with ATP as phosphate donor and with either $\mathrm{A}_{20}, \mathrm{dA}_{20}$, or both. T4 PNK was used as a positive control to validate the assay setup. The MmCNP domains were tested separately, with a negative result in the chosen assay conditions. The arrow represents the direction of electrophoresis. (PDF $387 \mathrm{~kb}$ )

\section{Abbreviations}

Bf: Branchiostoma floridae; BSA: Bovine serum albumin; cCMP: cyclic cytosine monophosphate; CNPase: 2',3'-cyclic nucleotide 3'-phosphodiesterase; CNS: Central nervous system; CPDase: Cyclic phosphodiesterase; DEPC: Diethylpyrocarbonate; DESY: Deutsches Elecktronen-Synchrotron; $D_{\text {max }}$ : maximum dimension of a particle; DNA: Deoxyribonucleic acid; DNase: Deoxyribonuclease; DTT: Dithiothreitol; E. coli: Eschericia coli; EDTA: Ethylenediaminetetraacetic acid; EMBL: European Molecular Biology Laboratory; GTP: Guanosine triphosphate; HEPES: Hydroxyethyl piperazineethanesulfonic acid; HIV: Human immunodeficiency virus; Hs: Homo sapiens; IPTG: Isopropyl $\beta$-D-1-thiogalactopyranoside; Mm: Mus musculus; $\mathrm{NADP}^{+}$: Oxidized form of nicotinamide adenine dinucleotide phosphate; NADPH: Reduced form of nicotinamide adenine dinucleotide phosphate; PCR: Polymerase chain reaction; PDB: Protein Data Bank; PNK: Polynucleotide kinase; PNS: Peripheral nervous system; PolyA: Polyadenylate; $R_{g}$ : Radius of gyration; RNA: Ribonucleic acid; RNase: Ribonuclease; SAXS: Small-angle X-ray scattering; Sc or S. cerevisiae: Saccharomyces cerevisiae; SDS-PAGE: Sodium dodecyl sulphatepolyacrylamide gel electrophoresis; SEC: Size exclusion chromatography; SLIC: Sequence and ligation independent cloning; SRCD: Synchrotron radiation circular dichroism; Trl1: tRNA ligase 1; tRNA: transfer ribonucleic acid; $\beta$-ME: Beta-mercaptoethanol.

\section{Acknowledgements}

We extend our special thanks to the beamline staff at EMBL-Hamburg/DESY, MAX-Lab, and ANKA, as well as to staff at the Biocenter Oulu Proteomics and Protein Analysis Core Facility.

\section{Funding}

This study has been supported by the Academy of Finland, the German Federal Ministry for Education and Research, and the Research and Science Foundation of the City of Hamburg (Germany). The funders had no role in the design of the study, the collection, analysis, and interpretation of data, or in writing the manuscript.

\section{Availability of data and materials}

All data generated or analysed during this study are included in the published article and its supplementary information files. Raw data files are available from the corresponding author on reasonable request.

\section{Authors' contributions}

GM planned and carried out experiments, analysed data, and was a major contributor in writing the manuscript. AR planned and carried out experiments, analyzed data, and participated in writing the manuscript. MM planned and carried out experiments, analysed data, and participated in writing the manuscript. IK obtained funding for the study, planned experiments, analysed data, and participated in writing the manuscript. PK obtained funding for the study, planned experiments and analysed data, and was a major contributor in writing the manuscript. All authors read and approved the final manuscript.

\section{Competing interests}

The authors declare that they have no competing interests.

\section{Consent for publication}

Not applicable.

\section{Ethics approval and consent to participate}

Not applicable.

\section{Publisher's Note}

Springer Nature remains neutral with regard to jurisdictional claims in published maps and institutional affiliations.

\section{Author details}

${ }^{1}$ Centre for Structural Systems Biology - Helmholtz Centre for Infection Research, German Electron Synchrotron (DESY), Hamburg, Germany. ${ }^{2}$ Faculty of Biochemistry and Molecular Medicine \& Biocenter Oulu, University of Oulu, Oulu, Finland. ${ }^{3}$ Department of Biomedicine, University of Bergen, Bergen, Norway.

Received: 19 March 2017 Accepted: 10 May 2017

Published online: 16 May 2017

\section{References}

1. Englert M, Beier H. Plant tRNA ligases are multifunctional enzymes that have diverged in sequence and substrate specificity from RNA ligases of other phylogenetic origins. Nucleic Acids Res. 2005;33:388-99.

2. Greer $\mathrm{CL}$, Peebles $\mathrm{CL}$, Gegenheimer P, Abelson J. Mechanism of action of a yeast RNA ligase in tRNA splicing. Cell. 1983;32:537-46.

3. Abelson J, Trotta CR, Li H. tRNA Splicing. J Biol Chem. 1998;273:12685-8.

4. Wang LK, Shuman S. Structure-function analysis of yeast tRNA ligase. RNA. 2005;11:966-75.

5. Wang LK, Schwer B, Englert M, Beier H, Shuman S. Structure-function analysis of the kinase-CPD domain of yeast tRNA ligase ( $\mathrm{Tr} / 1)$ and requirements for complementation of tRNA splicing by a plant Trl1 homolog. Nucleic Acids Res. 2006;34:517-27.

6. Filipowicz W, Shatkin AJ. Origin of splice junction phosphate in tRNAs processed by HeLa cell extract. Cell. 1983;32:547-57.

7. Zillmann M, Gorovsky MA, Phizicky EM. Conserved mechanism of tRNA splicing in eukaryotes. Mol Cell Biol. 1991;11:5410-6. 
8. Englert M, Sheppard K, Gundllapalli S, Beier H, Söll D. Branchiostoma floridae has separate healing and sealing enzymes for 5'-phosphate RNA ligation. Proc Natl Acad Sci U S A. 2010;107:16834-9.

9. Nasr F, Filipowicz W. Characterization of the Saccharomyces cerevisiae cyclic nucleotide phosphodiesterase involved in the metabolism of ADP-ribose 1",2"-cyclic phosphate. Nucleic Acids Res. 2000;28:1676-83.

10. Mazumder R, lyer LM, Vasudevan S, Aravind L. Detection of novel members, structure-function analysis and evolutionary classification of the $2 \mathrm{H}$ phosphoesterase superfamily. Nucleic Acids Res. 2002;30:5229-43.

11. Walker JE, Saraste M, Runswick M, Gay NJ. Distantly related sequences in the alpha- and beta-subunits of ATP synthase, myosin, kinases and other ATP-requiring enzymes and a common nucleotide binding fold. EMBO J. 1982;1:945-51.

12. Wang LK, Shuman S. Domain Structure and Mutational Analysis of T4 Polynucleotide Kinase. J Biol Chem. 2001;276:26868-74.

13. Galburt EA, Pelletier J, Wilson G, Stoddard BL. Structure of a tRNA repair enzyme and molecular biology workhorse: T4 polynucleotide kinase. Structure. 2002;10:1249-60

14. Wang $L K$, Lima CD, Shuman S. Structure and mechanism of T4 polynucleotide kinase: An RNA repair enzyme. EMBO J. 2002;21:3873-80,

15. Wang LK, Shuman S. Mutational analysis defines the 5'-kinase and 3'phosphatase active sites of T4 polynucleotide kinase. Nucleic Acids Res. 2002;30:1073-80.

16. Sawaya R, Schwer B, Shuman S. Genetic and biochemical analysis of the functional domains of yeast tRNA ligase. J Biol Chem. 2003;278:43928-38.

17. Westaway SK, Belford HG, Apostol BL, Abelson J, Greer CL. Novel activity of a yeast ligase deletion polypeptide: Evidence for GTP-dependent tRNA splicing. J Biol Chem. 1993;268:2435-43.

18. Myllykoski M, Seidel L, Muruganandam G, Raasakka A, Torda AE, Kursula P. Structural and functional evolution of 2',3'-cyclic nucleotide $3^{\prime}-$ phosphodiesterase. Brain Res. 2016;1641(A):64-78.

19. Bifulco M, Laezza C, Stingo S, Wolff J. 2',3'-Cyclic nucleotide 3'-phosphodiesterase: a membrane-bound, microtubule-associated protein and membrane anchor for tubulin. Proc Natl Acad Sci U S A. 2002;99:1807-12.

20. Lappe-Siefke C, Goebbels S, Gravel M, Nicksch E, Lee J, Braun PE, et al. Disruption of Cnp1 uncouples oligodendroglial functions in axonal support and myelination. Nat Genet. 2003;33:366-74.

21. Muraro PA, Kalbus M, Afshar G, McFarland HF, Martin R. T cell response to 2', $3^{\prime}$-cyclic nucleotide $3^{\prime}$-phosphodiesterase (CNPase) in multiple sclerosis patients. J Neuroimmunol. 2002;130:233-42.

22. Peirce TR, Bray NJ, Williams NM, Norton N, Moskvina V, Preece A, et al. Convergent evidence for 2',3'-cyclic nucleotide 3'-phosphodiesterase as a possible susceptibility gene for schizophrenia. Arch Gen Psychiatry. 2006;63:18-24.

23. Wilson SJ, Schoggins JW, Zang T, Kutluay SB, Jouvenet N, Alim MA, et al. Inhibition of HIV-1 particle assembly by 2,3'-cyclic-nucleotide 3'phosphodiesterase. Cell Host Microbe. 2012;12:585-97.

24. Drummond Gl, lyer NT, Keith J. Hydrolysis of Ribonucleoside 2',3'-Cyclic Phosphates by a Diesterase from Brain. J Biol Chem. 1962;237:3535-9.

25. Kozlov G, Lee J, Elias D, Gravel M, Gutierrez P, Ekiel I, et al. Structural Evidence That Brain Cyclic Nucleotide Phosphodiesterase Is a Member of the 2H Phosphodiesterase Superfamily. J Biol Chem. 2003;278:46021-8.

26. Sakamoto Y, Tanaka N, Ichimiya T, Kurihara T, Nakamura KT. Crystal structure of the catalytic fragment of human brain 2',3' -cyclic-nucleotide $3^{\prime}$ -phosphodiesterase. J Mol Biol. 2005;346:789-800.

27. Myllykoski M, Raasakka A, Han H, Kursula P. Myelin 2',3' -cyclic nucleotide $3^{\prime}$ -phosphodiesterase: Active-site ligand binding and molecular conformation. PLoS One. 2012;7(2):e32336.

28. Myllykoski M, Raasakka A, Lehtimäki M, Han H, Kursula I, Kursula P. Crystallographic analysis of the reaction cycle of 2',3'-cyclic nucleotide $3^{\prime}-$ phosphodiesterase, a unique member of the $2 \mathrm{H}$ phosphoesterase family. J Mol Biol. 2013;425:4307-22

29. Raasakka A, Myllykoski M, Laulumaa S, Lehtimäki M, Härtlein M, Moulin $M$, et al. Determinants of ligand binding and catalytic activity in the myelin enzyme 2',3'-cyclic nucleotide 3'-phosphodiesterase. Sci Rep. 2015;5:16520.

30. Myllykoski M, Kursula P. Expression, purification, and initial characterization of different domains of recombinant mouse 2',3'-cyclic nucleotide 3'phosphodiesterase, an enigmatic enzyme from the myelin sheath. BMC Res Notes. 2010;3:12

31. Stingo S, Masullo M, Polverini E, Laezza C, Ruggiero I, Arcone R, et al. The Nterminal domain of 2',3'-cyclic nucleotide 3'-phosphodiesterase harbors a GTP/ATP binding site. Chem Biol Drug Des. 2007;70:502-10.
32. Myllykoski M, Itoh K, Kangas SM, Heape AM, Kang SU, Lubec G, et al. The Nterminal domain of the myelin enzyme 2',3'-cyclic nucleotide 3'phosphodiesterase: Direct molecular interaction with the calcium sensor calmodulin. J Neurochem. 2012;123:515-24.

33. Snaidero $N$, Velte $C$, Myllykoski M, Raasakka A, Ignatev A, Werner HB, et al. Antagonistic Functions of MBP and CNP Establish Cytosolic Channels in CNS Myelin. Cell Rep. 2017;18:314-23.

34. Mooij WTM, Mitsiki E, Perrakis A. ProteinCCD: Enabling the design of protein truncation constructs for expression and crystallization experiments. Nucleic Acids Res. 2009;37:W402-5.

35. Lees JG, Smith BR, Wien F, Miles AJ, Wallace BA. CDtool—an integrated software package for circular dichroism spectroscopic data processing, analysis, and archiving. Anal Biochem. 2004;332:285-9.

36. Lobley A, Whitmore L, Wallace BA. DICHROWEB: an interactive website for the analysis of protein secondary structure from circular dichroism spectra. Bioinformatics. 2002;18:211-2.

37. Lee J, Gravel M, Gao E, O'Neill RC, Braun PE. Identification of essential residues in 2',3'-cyclic nucleotide 3'-phosphodiesterase. Chemical modification and sitedirected mutagenesis to investigate the role of cysteine and histidine residues in enzymatic activity. J Biol Chem. 2001;276:14804-13.

38. Sogin DC. 2',3'-cyclic NADP as a substrate for $2,3^{\prime}$-cyclic nucleotide $3^{\prime}$ phosphohydrolase. J Neurochem. 1976;27:1333-7.

39. Ericsson UB, Hallberg BM, DeTitta GT, Dekker N, Nordlund P. Thermofluorbased high-throughput stability optimization of proteins for structural studies. Anal Biochem. 2006;357:289-98.

40. Konarev PV, Petoukhov MV, Volkov W, Svergun DI. ATSAS 2.1, a program package for small-angle scattering data analysis. J Appl Crystallogr. 2006;39:277-86.

41. Majava V, Petoukhov MV, Hayashi N, Pirilä P, Svergun DI, Kursula P. Interaction between the $\mathrm{C}$-terminal region of human myelin basic protein and calmodulin: analysis of complex formation and solution structure. BMC Struct Biol. 2008:8:10.

42. Majava V, Wang C, Myllykoski M, Kangas SM, Kang SU, Hayashi N, et al. Structural analysis of the complex between calmodulin and full-length myelin basic protein, an intrinsically disordered molecule. Amino Acids. 2010;39:59-71.

43. Konarev PV, Volkov W, Sokolova AV, Koch MHJ, Svergun DI. PRIMUS: A Windows PC-based system for small-angle scattering data analysis. J Appl Crystallogr. 2003;36:1277-82.

44. Svergun DI. Determination of the regularization parameter in indirect-transform methods using perceptual criteria. J Appl Crystallogr. 1992;25:495-503.

45. Franke D, Svergun DI. DAMMIF, a program for rapid ab-initio shape determination in small-angle scattering. J Appl Crystallogr. 2009;42:342-6.

46. Volkov W, Svergun DI. Uniqueness of ab initio shape determination in small-angle scattering. J Appl Crystallogr. 2003;(36):860-4.

47. Svergun DI, Petoukhov MV, Koch MH. Determination of domain structure of proteins from X-ray solution scattering. Biophys J. 2001;80:2946-53.

48. Svergun DI. Restoring Low Resolution Structure of Biological Macromolecules from Solution Scattering Using Simulated Annealing. Biophys J. 1999;76:2879-86.

49. Bekesi A, Pukancsik M, Haasz P, Felfoldi L, Leveles I, Muha V, et al. Association of RNA with the uracil-DNA-degrading factor has major conformational effects and is potentially involved in protein folding. FEBS J. 2011;278:295-315.

50. Gravel M, Robert F, Kottis V, Gallouzi I-E, Pelletier J, Braun PE. 2',3'-Cyclic nucleotide $3^{\prime}$-phosphodiesterase: A novel RNA-binding protein that inhibits protein synthesis. J Neurosci Res. 2009;87:1069-79.

51. Myllykoski M, Kursula P. Structural aspects of nucleotide ligand binding by a bacterial 2H phosphoesterase. PLoS One. 2017;12:e0170355.

52. Schwer B, Aronova A, Ramirez A, Braun P, Shuman S. Mammalian 2',3' cyclic nucleotide phosphodiesterase (CNP) can function as a tRNA splicing enzyme in vivo. RNA. 2008;14:204-10.

53. Kelley LA, Sternberg MJE. Protein structure prediction on the Web: a case study using the Phyre server. Nat Protoc. 2009:4:363-71.

54. Notredame C, Higgins DG, Heringa J, Notredame C, Higgins DG, Heringa J. T-coffee: a novel method for fast and accurate multiple sequence alignment. J Mol Biol. 2000;302:205-17. 